\title{
Lessons learned using dSedNet plug-in within a water supply catchment for Greater Sydney
}

\author{
$\underline{\text { Suraya Amini }}^{\mathrm{a}}$, Jordan Pont ${ }^{\mathrm{a}}$, Marlène van der Sterren ${ }^{\mathrm{a}}$ and Andrew Freebairn ${ }^{\mathrm{b}}$ \\ ${ }^{a}$ WaterNSW, Sydney Australia \\ ${ }^{b}$ CSIRO, Canberra \\ Email: marlene.vandersterren@waternsw.com.au
}

\begin{abstract}
Previous studies have identified that water quality in lakes and reservoirs can be closely associated with the hydrologic regime of flood and drought events. Extended low flow events can change the driving mechanisms of water quality constituents, particularly sediment loads, due to increased residence times and reduction in flushing. WaterNSW is developing a catchment to supply water quality and quantity model for the Greater Sydney supply system. The modelling of sediment within the water column and runoff profile is deemed critical to manage good quality water supplies.

Key drivers of total suspended solids within the water column are hill slope, gully and stream erosion. These processes are further exacerbated by a lack of ground cover post bush fire in WaterNSW's heavily forested catchments. This paper explores the use of the CSIRO dSedNet plugin in the eWater Source program and the challenges faced adopting them in the Warragamba and Avon catchment models.

This study highlights the importance of setting up modelling files within the right context and ensuring data integrity throughout the spatial data. WaterNSW worked with CSIRO to update the help files and documentation to assist others in taking up more detailed sediment modelling within catchments.
\end{abstract}

Keywords: Sediment, modelling, Source, SedNet plugin 


\section{INTRODUCTION}

In accordance with the Australian Drinking Water Guidelines (National Health and Medical Research Council and National Resource Management Ministerial Council, 2011), an understanding of water quality needs to be established. An integrated tool to assess the risks and benefits to different management practices is in development to facilitate informed long-term decision making for catchment protection and water supply systems in the Greater Sydney water supply system, on both a water quality and financial basis. Models within the operational system will simulate the river, catchment, and reservoir processes of water quality and quantity (Paredes-Arquiola et al., 2010). The model's goal is to improve the capability of planning catchment programs, operational decision making for supply water quality and assist in quantifying the benefits of protecting the water within the drinking water catchments for water supply, reservoir management and longterm treatment benefits. Model calibration and validation are an inherent component of water quality model construction, requiring the comparison of measured and modelled constituent data. These can present a challenge when dealing with water quality variables(Moriasi et al., 2007).

Among the water quality variables from catchment runoff, both suspended and dissolved solids affect water quality (Franson, 2005). The solids can reduce light penetration, affect aquatic life forms, increase turbidity and absorb toxins (Dennison, 1996). Total Suspended Solids (TSS) include particles that settle in the receiving water, which can cause a significant amount of harm to the benthic zone and aquatic life. In addition, inorganics, especially heavy metals, often adhere to TSS due to the effectively larger surface areas (Ball, 2000). As a result, TSS from erosion can have a direct impact on the receiving water quality. TSS are generated from erosion processes, which include stream and gully erosion with the Greater Sydney water supply catchments.

In 2005/2006, the Sydney Catchment Authority (SCA) - a predecessor organization of WaterNSW- undertook comprehensive remote sensing studies to map active gullies. Initial field assets confirmed that the methodology of the remote sensing studies undertaken in 2005/2006 was suitable to identify gully erosion (Knight et. al., 2007). Previous modelling conducted on the Burragarong catchment (Warragamba) also identified a relatively high sediment rate from forested catchments near the reservoir. Previous modelling of sediment and nutrient budgets in the Lake Burragorang catchment (Rustomji, 2007) identified that the intra-catchment variation in both hill slope and gully erosion could be improved in subsequent models. Erosion is dependent on ground cover (Blue Book 2004). When ground cover is missing due to bushfire (Visentin et al., 2019), the impact of erosion on the receiving water is quite evident in measured TSS water quality profiles.

Model accuracy drives the need to find a methodology suitable to model the potential erosion of multiple landuses across the catchments. WaterNSW is currently developing integrated catchment modelling tools to describe the processes and the challenges of catchment management and inflows to the reservoir. Key requirements for the model are to be able to model the hill, gully and stream erosion for the current land-uses and modified landuses such as hazard reduction burns and post-fire periods. The models are developed in the eWater Source modelling platform using the CSIRO dSedNet Plugin for erosion modelling. This paper highlights the challenges encountered and solutions for the application of dSedNet plugin in the eWater Source modelling software.

\section{MODELLING DOMAIN}

The Greater Sydney water supply system consists of a network of 21 dams and reservoirs, from five catchment areas, covering $16,000 \mathrm{~km}^{2}$. For this study, Warragamba, and Avon catchments were selected for analysis (Figure 1). Warragamba is the largest dam in the system, located $65 \mathrm{~km}$ west of Sydney, holding approximately $80 \%$ of the water supply for Sydney. Avon Dam is located $100 \mathrm{~km}$ south of Sydney and is the main water supply for the Illawarra region, south of Sydney CBD. Avon is the second largest dam in the system but has a smaller catchment area. 


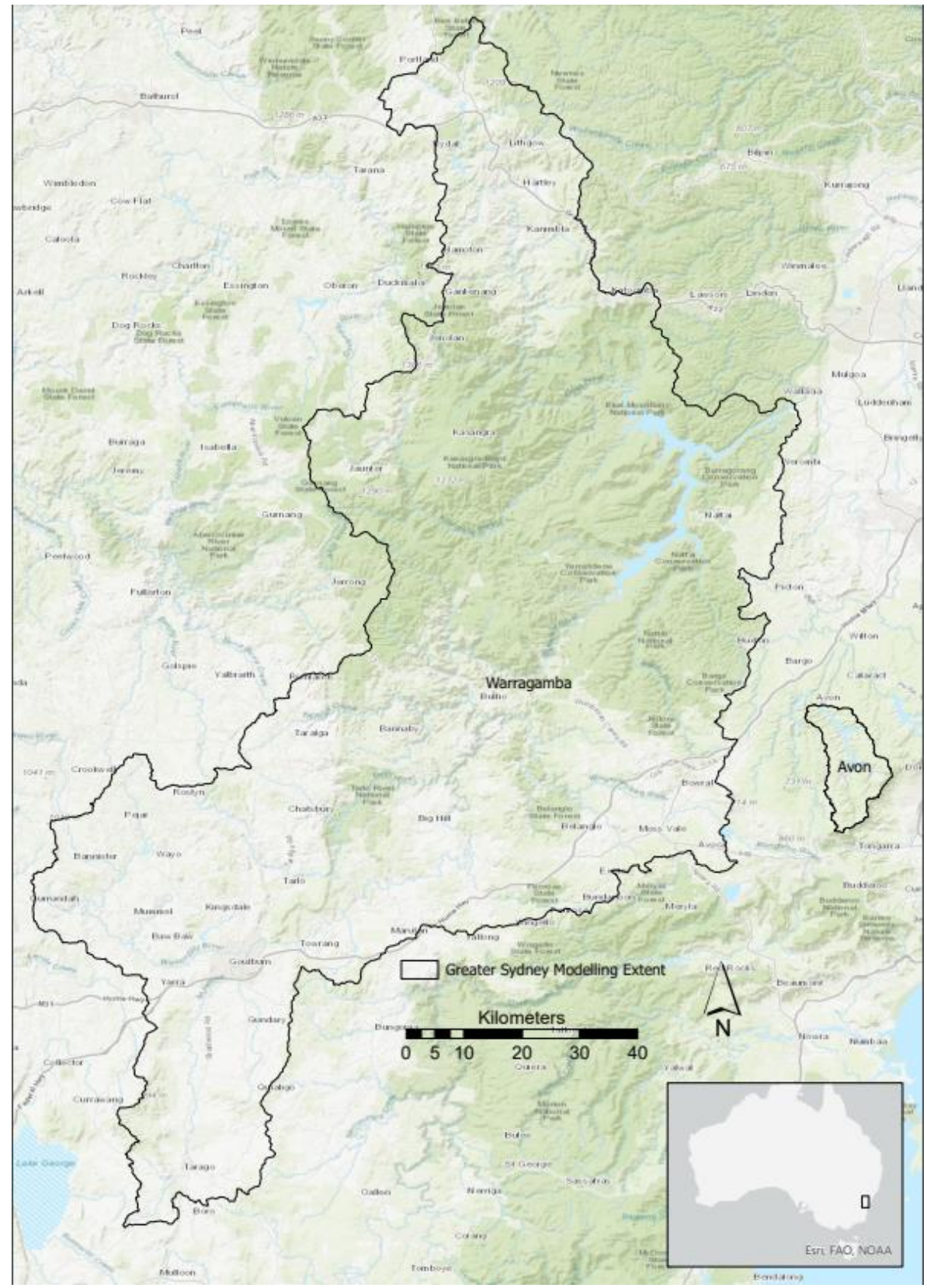

Figure 1. Location of study area, indicating Greater Sydney Modelling extent, and selected catchments.

\section{DATA PREPARATION FOR EROSION MODELLING}

\subsection{Data Pre-processing}

Pre-processing and data analysis were carried out in the desktop GIS software ArcGIS Pro, developed and managed by ESRI. Terrain pre-processing and watershed delineation were carried out using the tools in the ArcHydro Toolbox suite and a 5m resolution Digital Elevation Model (DEM). The dendritic ArcHydro processing workflow was applied to a hydrologically corrected DEM. Landuse data for the assignment of Functional Units (FU) (I.e., land use units showing classified land use types) was obtained from the NSW 2017 Landuse mapping dataset (NSW Department of Planning, Industry and Environment (DPIE), 2020) and clipped to the defined boundaries of each subcatchment.

Data was corrected prior to use in eWater Source, for extent, projection, cell size and null values in accordance with the CSIRO dSedNet User Documentation (Freebairn et.al 2015). Final layers were exported as gridded datasets in a .tif format for use in eWater Source. Soil and erosion data for hillslope erosion, gully erosion and streambank erosion models were sourced from the CSIRO Maps of Australia soil loss Maps (Viscarra Rossel et. al., 2016) and the Soil and Landscape Grid nation Soil Attribute Maps (Viscarra Rossel, 2014). 


\subsection{Gully erosion versus hillslope erosion}

The dSedNet plugin addresses Hillslope, Gully and Streambank erosion using three separate models. Gully network mapping was carried out to partition spatial data to align with each respective erosion model. In the absence of complete gully mapping across the Avon and Warragamba water supply catchments, a review of currently available hydroline datasets was undertaken to identify the association between stream order and gully determination.

A previous paper addressing the implementation of the dSedNet plugin written by Cuddy et.al. (2019) explains how the Western Port modelling for Melbourne Water Corporation derived gully data from in situ field mapping. This was cross examined with visual interpretation of ESRI aerial base maps and high-resolution aerial imagery.

For the purpose of erosion mapping within the project, the internal data was reviewed to determine the most suitable data source for mapping gully networks within each catchment. A partially compete gully map dataset captured from 2008 - 2019 and analyzed by Bickmore (2012), was acquired from in field sampling and desktop analysis using sub-meter Aerial Photography. This was compared against an existing stream network Hydroline derived from the $5 \mathrm{~m}$ DEM.

A high degree of similarity was apparent when visually comparing the field data with the derived remotely sensed hydroline data. The strong correlation between in field gully data and the remotely sensed derived hydroline data lead to the justification to implement the dataset. The Hydroline was used for gully mapping across the entirety of the study area in the absence of adequate in situ data.

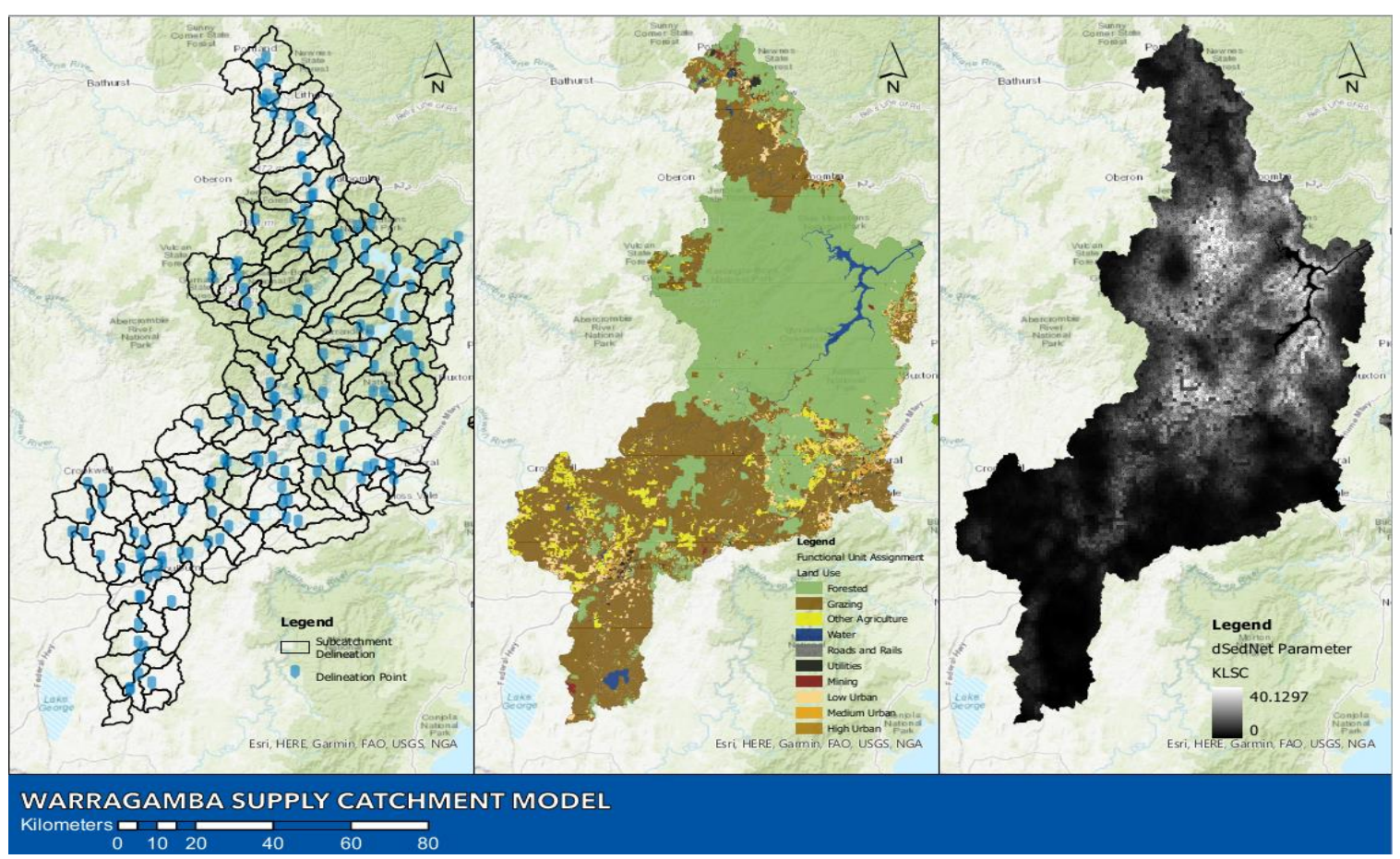

Figure 2. Supply Catchment Modelling for Warragamba depicting the Model Build with Subcatchment Watershed, Functional Unit Assignment and dSedNet KLSC Parameter. 


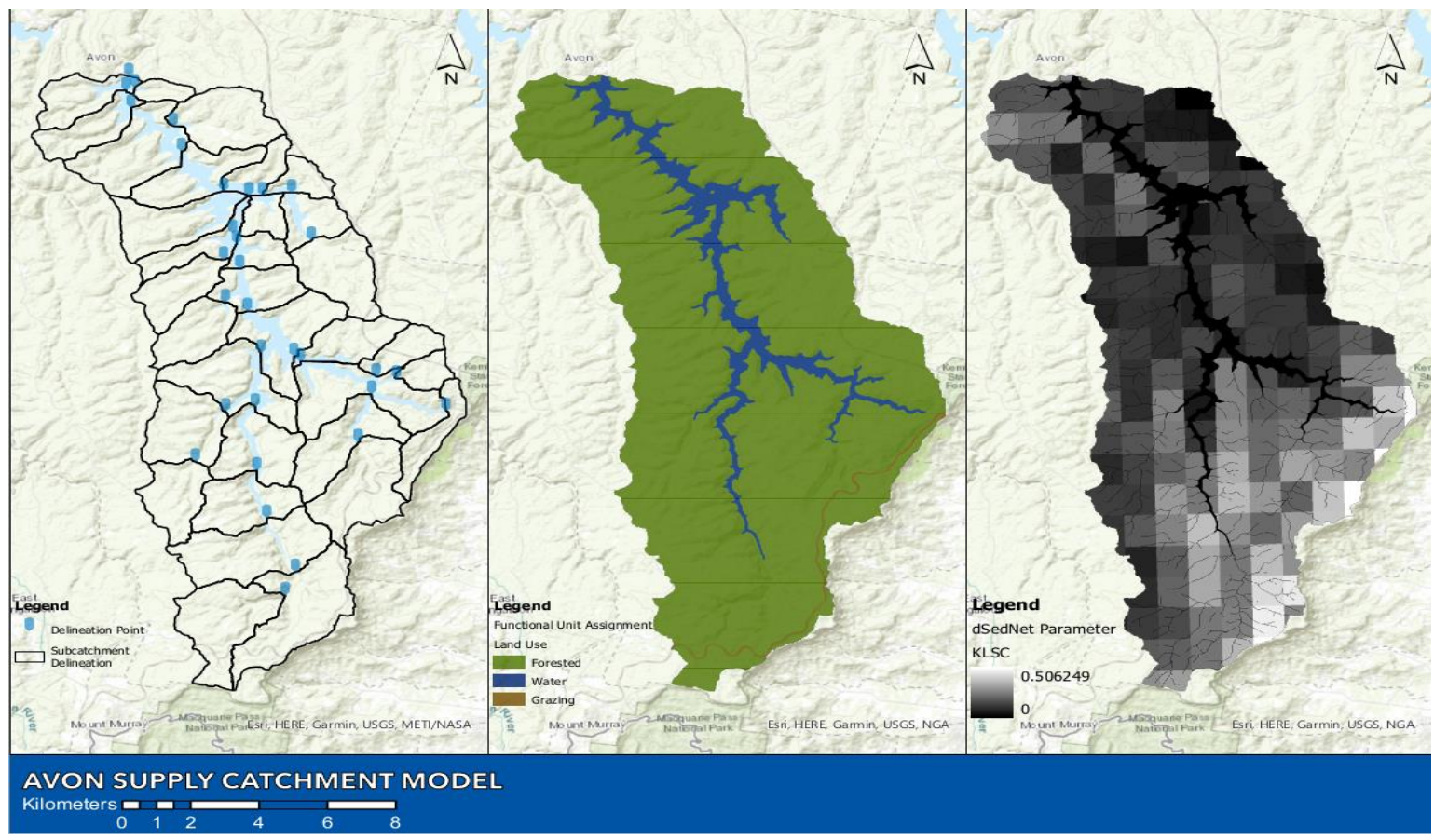

Figure 3. Supply Catchment Modelling for Avon depicting the Model Build with Subcatchment Watershed, Functional Unit Assignment and Gully and dSedNet KLSC Parameter.

Dense native canopy cover present across the study area limited the application of high-resolution aerial imagery in discerning active from non-active gully erosion. In the absence of on ground field data, the Strahler stream order classification system was used to define the relationship between stream order and gully determination. It was observed that mapped gullies and stream orders classified in the Hydroline data below a 1st Order stream, were indicative of ephemeral creeks and gully depressions.

Associated project erosion data was pre-processed in ArcGIS Pro, using a combination of data management and spatial analyst functions to derive the desired outputs required for input into the dSedNet spatial parameteriser. Hillslope, Gully and Streambank Model data sets were separated using a derived Hydroline dataset and Map algebra expressions to set the corresponding cell values to 0 within each parameter output for the respective models.

\section{CHALLENGES AND THEIR SOLUTIONS}

\subsection{Gaps in the data}

Initial delays and challenges in uploading GIS files can be attributed to a lack of understanding of eWater Source configuration with the dSedNet Plugin. These challenges were resolved by understanding the requirements that gridded data sets must be comparable to each other in respect to extent, projection, cell size and null value. The dSedNet Plugin requires a high level of specificity regarding these parameters and will not process the input gridded dSedNet data if discrepancies between layers are present. This was resolved during the GIS pre-processing stage by manipulating the GIS tool's environment settings and the implementation of a preconfigured mask raster created from the watershed delineated Sub-catchment layer.

Further challenges arose from error propagations during the vector to raster conversion of the Sub-catchment Watershed and Land-Use vector layers. Null data gaps were introduced into the input Sub-Catchment and LandUse gridded data due to the presence of slivers and gaps in the vector layers. The dSedNet spatial parameteriser operates on the logic that the model has continuous data across the study area, layers are comparable and null value cells are not contained within the extent of the study area. FUs have been previously defined based on a spatial process and the spatial parameteriser needs to adhere to this so that the FU models are parameterised correctly.

To resolve this issue, the robust topological validation process was implemented to detect and resolve overlapping polygons and feature gaps. Topology validation was carried out during data pre-processing using ESRI's Validate Topology tool in ArcGIS Pro. A computer automated process was necessary to identify the minute discrepancies between objects not apparent to visual analysis. 


\subsection{Error Identification}

The source and interpretation of errors was often difficult to diagnose within the eWater Source modelling platform. A Spatial Compatibility Error was indicated through a generalized error message 'Data is not compatible with existing spatial data' presented when inputting gridded erosion data into one of the dSedNet parameters. Alternatively, and hard to diagnosis is a Model Crash Error that presents when inputting gridded erosion data into the dSedNet spatial parameteriser causing Source to crash.

The Spatial Compatibility Error can be attributed to the following issues between the Sub-catchment, Land-Use and dSedNet Erosion Parameter:

- The projection systems are not aligned

- Cell size is not consistent between layers

- The extent of each layer doesn't match

- The define null value is not configured to the default Source input (e.g. -9999).

This can be corrected though properly setting up each gridded dataset. The most practical method determined during the project was to create a mask layer derived from the Watershed delineation and configured to the default setup. This default parameter mask layer was input into each successive GIS tool step's environment settings (i.e., the options pane) to replicate the same parameters and provide consistency during pre-processing.

The Model Crash Error was attributed to one of two causes, the first being the FU raster mapping was not properly assigned during the model build, this consequently cause the plugin code to crash. The FU raster needs to be saved, otherwise it is not available for the spatial parameteriser to be used. This results in the raster being visible in the spatial data sets within Source.

It should be noted that the CSIRO dSedNet plugin will only work after the constituent models have been setup for TSS and that the computations will not run unless the appropriate rainfall runoff systems are included in the model setup.

\section{RESULTS / OUTCOME}

An adaptive model approach was applied for the Water Modelling of each catchment, taking on the learnings from each successive iteration and accompanied failings to further refine the generation of model inputs. A collaborative effort with CSIRO dSedNet developers', analysis of the plugins code further refined the error troubleshooting.

The end sum of work and effort dedicated to the project's objective to model erosion and sediment utilising the dSedNet plugin for the Warragamba and Avon supply catchment culminated in the successful generation of Hillslope and Gully Erosion parameters and subsequent model calibration in eWater Source. Currently calibration of the models are in progress across the Greater Sydney water supply catchments.

As a result of the project and challenges faced, the dSedNet guidance documentation has been updated to reflect the lessons learned and provide instructions for a range of user levels. Initial modelling for hillslope erosion with the Avon catchment boundary is showing reasonable results without detailed calibration.

\section{REFERENCES}

2004. Managing Urban Stormwater: Soils and Construction, Landcom, Parramatta: New South Wales Government.

Ball, J. E. 2000. Modelling contamination in stormwater runoff. 3rd International Hydrology and Water Resources Symposium. Perth: The Institution of Engineers Australia.

Bickmore, J. (2012) Gully Erosion Mapping for Risk Assessment in Sydneys Drinking Water Catchments, Sydney Catchment Authority.

Cuddy, S., Weber, T., Cetin, L., Wilkinson, S., Gonzalez, D., Freebairn, A., Coleman, R., Gamboa, R., Thew, P., Rahman, J. (2019) Exploring options to manage sediment loads to Western Port: further development and application of dSedNet in an urban-rural dominated catchment. Report for Melbourne Water Corporation, CSIRO, Australia.

Dennison, M. S. (1996) Stormwater discharges regulatory compliance and best management practices, Boca Raton, USA, CRC Press Inc.

Franson, M. A. H. (ed.) (2005) Standard methods for the examination of water and wastewater, Washington: American Public Health Association. 
Freebairn, A., Fleming, N., Van Der Liden, L., He, Y., Cuddy, S., Cox, J., Bridgart, R. (2015) Extending the Water Quality modelling Capability within eWater Source - Developing the dSedNet plugin, Goyder Institute for Water Research Technical Report Series No. 15/42, Adelaide, South Australia.

Knights, P., Mathers, M., Scott, B., Raphel, N. (2007) Decision Support System for Rectification Action Planning (RPDASS), Gully and Streambank Erosion Module, Sydney Catchment Authority.

Moriasi, D. N., Arnold, J. G., Van Liew, M. W., Bingner, R. L., Harmel, R. D. \& Veith, T. L. 2007. Model evaluation guidelines for systematic quantification of accuracy in watershed simulations. American Society of Agricultural and Biological Engineers, 50, 885-900.

National Health and Medical Research Council \& National Resource Management Ministerial Council (2011) Australian Drinking Water Guidelines Paper 6 National Water Quality Management Strategy. Canberra: Commonwealth of Australia.

Paredes-Arquiola, J., Andreu-Alvarez, J., Martin-Monerris, M., Solera, A. (2010) Water quantity and quality models applied to the Jucar River Basin, Spain. Water Resources Management, 24, 2759-2779.

Rustomji, P.(2007) Modelling sediment and nutrient budgets in the Lake Burragorang catchment. Sydney Catchment Authority, Penrith: CSIRO.

State Government of NSW and Department of Planning, Industry and Environment. (2020) NSW Landuse 2017 v1.2, Landuse Mapping for NSW 2017. [online] Available at: https://datasets.seed.nsw.gov.au/dataset/nswlanduse-2017-v1p2-f0ed [Accessed Jan. 2021].

Visentin, L, Clun, R., Power, J (2019) Bushfires threaten Sydney's drinking water supply. Sydney Morning Herald, 27 December 2019.

Viscarra Rossel, R., Teng, H., Zhou, S., Behrens, T., Chappell, A., Bui, E. (2016) Maps of Australian soil loss by water erosion derived using the RUSLE. v1, CSIRO. Available at: https://doi.org/10.4225/08/582cef2dd5966 [Accessed Jan. 2021].

Viscarra Rossel, R., Chen, C., Grundy, M., Searle, R., Clifford, D., Odgers, N., Holmes, K., Griffin, T., Liddicoat, C., Kidd, D. (2014) Soil and Landscape Grid National Soil Attribute Maps - Bulk Density Whole Earth (3" resolution) - Release 1. v5, CSIRO. Available at: https://doi.org/10.4225/08/546EE212B0048 [Accessed Jan. 2021].

\section{ACKNOWLEDGEMENT}

WaterNSW would like to acknowledge the assistance received from CSIRO, in particular the support and assistance from Susan Cuddy, Team Leader, Water Security CSIRO Land and Water. 